\title{
Editorial: Food water energy for all
}

\author{
Runa Sarkar • Paul Shrivastava
}

Published online: 27 May 2015

(C) Indian Institute of Management Calcutta 2015

There is growing global anxiety about the future of planet earth. The unprecedented population growth currently over 7 billion and expected to grow to 10 billion begs the questions of will there be enough food to feed everybody, will there be enough water, energy and land to meet agricultural needs and will urban spaces be livable. Will we be able to prevent destruction of key ecosystems, natural forests, lakes, mountains and deserts? Food energy and water have emerged as a key concern for the future. The FAO has defined food security as 'availability and access to sufficient, safe and nutritious food to meet the dietary needs and food preferences for an active and healthy life' (UN General Assembly 2010). We interpret energy and water security as access to clean, reliable and affordable energy to meet human needs and as access to water for human use (including drinking water and sanitation) and ecosystem services, respectively. The three resources are inextricably connected to each other. One could think of (solar) energy and water being responsible for 'creation' of food as a resource through the process of photosynthesis, or for

R. Sarkar $(\bowtie)$

Economics Group, Indian Institute of Management

Calcutta, D H Road, Kolkata 700104, India

P. Shrivastava $(\square)$

John Molson School of Business, Concordia University,

Montreal, QC, Canada

e-mail: paul.shrivastava@concordia.ca facilitating the growing of food through irrigation which requires electricity. The Future Earth global environmental change research program has highlighted the importance of thinking about these issues in a connected manner.

The Food-Water-Energy nexus concept has now emerged as a valuable new step in connected transdisciplinary thinking in sustainability sciences. The concept was popularized by the Bonn 2011 Nexus conference (http://www.water-energy-food.org/en/). In the same year, the World Economic Forum issued its Global Risks report. While it is being increasingly acknowledged that cross-sectoral and trans-disciplinary approaches are needed, we are yet to develop a coherent and comprehensive framework of the complex dynamics (with feedback mechanisms) underlying these systems. We do not have adequate governance mechanism, integrated strategies and best practices, tools and analyses, and collaborative action from all sectors and actors. Academics, governments at federal provincial and municipal levels, the private sector and civil society organizations all have a crucial role to play in developing nexus thinking and nexus practices.

The challenge for food energy and water security globally has expanded from just unequal access to resource availability itself as the global ecosystem is increasingly stretched to provide ecosystem services. The current global development trajectory threatens to drive ecological systems at all scales towards critical 
thresholds from which recovery would be near impossible. Thus, managing these resources in a manner that is not detrimental to human welfare is the need of the hour. In addition to the conventional supply side management to ease resource availability, there is a need for demand side measures including improving the efficiency of resource use, sustainable consumption and understanding the interdependencies of the resources and leveraging these to improve availability, affordability and access.

The recently proposed set of Sustainable Development Goals (17 in number with 169 targets) build on the Millennium Development Goals and converge on global development agenda post 2015. They cover a broad range of sustainability issues and explicitly recognize the nexus between the different challenges facing the world. These goals can go a long way to set up an institutional framework and foundation to address the interspatial and intertemporal equity issues of resource distribution as well as pave the way forward to identify alternate sources for these resources, so that they remain affordable.

This calls for more integrated policy- and decisionmaking that account for external costs across sectors, space or time (such as the depletion of ground water and waste of water in general when electricity is supplied free of cost to farmers so as to boost their agricultural yields) to complement conventional approaches aimed at improving resource productivity in different sectors individually. Further, the institutions involved in resource management institutions need to be flexible, adaptive and enabled to cooperate with those from other sectors because accelerated rates of development lead to newer challenges and policy changes need to be proactive. Although there are some integrated frameworks such as the Integrated Natural Resources Management in place, their mandates need to be revisited to introduce an ecosystem-centric process into their operations. A clear need for a coordinated and harmonized nexus knowledge base through detailed life-cycle analyses is evident to identify the positive and negative externalities of any development decision.

The Bonn 2011 Nexus Conference called for all stakeholders to initiate the process of developing strategies that use the nexus approach to address the challenges of food energy and water availability, accessibility and affordability. Since then, there has been a lot of work, both empirical and theoretical, in this area. The discourse on formulation of the Sustainable Development Goals along with concerns on their efficacy and effectiveness has been lively, encompassing people from different walks of life. Science has a crucial role in coming up with solutions as do policy-makers, social scientists and regulators who design interventions. Businesses can play a role by re-crafting their strategies in adopting clean technologies and changing the mix of products they make. Towards this end, the Centre for Development and Environment Policy (CDEP) of IIM Calcutta held an International Conference on Managing Critical Resources: Food, Energy and Water in April 2015. This special issue of Decision takes the discussion amongst over 70 delegates at the conference forward to all readers of the journal.

It is aimed at bringing together this diverse set of stakeholders and presenting their experiences, thoughts, policy prescriptions and points of view in one place, highlighting both the nexus between food energy and water and to encourage dialogue between different disciplines on these interconnected issues. The ultimate objective was to take tiny steps to devise the way forward to resolve the ecological problems that unfettered development over the past century has resulted in, while ensuring unhampered improvement in the quality of humankind. Selected papers from the conference are also featured in this issue.

This special issue is divided into four sections, the Reflections Section, Research Papers, a Case Study and a Book Review Section. In Reflections, Professor Anup Sinha, coordinator of the CDEP interviews Professor Ramprasad Sengupta, Professor Emeritus, Jawaharlal Nehru University, Distinguished Fellow, India Development Foundation and advisor to the Planning Commission in the past on his views on the food energy and water nexus. According him, food energy and water are critical as they are the primary inputs for all economic activities, and form the basic life support system. Of these, energy is primarily responsible for the production of food with water, which gives it primacy. Today's industrial society is based on fossil fuel-based energy, but there is a need to transit to renewable sources of energy such as solar, wind and geothermal energy. However, the possibility of negative externalities arising from the use of these renewable energy sources cannot be overlooked, and human ingenuity is capable of overcoming the challenge of dwindling critical resources that we are grappling with. 
True to the multidisciplinary theme of the special issue, the range of research papers is diverse. To start with, Banerjee and Bit underline the need for an integrated policy position towards forest conservation that is consistently designed using input-output analysis to demonstrate that at present India's demand for forestry-based products is being met by imports, which implies a reduced stock of natural forest of the other countries. The relationship of direct forest intensity to gross domestic product reveals the increasing dominance of economic growth over other effects, undermining long run sustainability. Balaji, Ganapuram and Devakumar touch upon the food security issue, starting with the dismal state of affairs of global food security and then emphasize how the situation is most grim in South Asia, with climate change posing an additional challenge. They then suggest how ICT can be used to address the food security and nexus challenge, demonstrating this through two case studies of actual interventions in India. While these authors suggest MOOCs as a means of raising awareness among people on sustainability issues, the paper by Parashar, An Ecocritical Reading of T S Eliot's The Wasteland, helps raise a collective environmental conscience through exposing humankinds' callousness towards nature.

Continuing with the theme of energy security from our Reflections section, M G Reddy, B. S. Reddy and S R Padakandala review the experiences of biofuel cultivation in India over the past two decades in the context of impact on land use, rural livelihoods and the environment. A focused case study of villages in Madhya Pradesh was also conducted, through which the authors demonstrate the futility of ensuring energy security by producing biofuels, due to the long-term deleterious impact on food and fodder security for people and livestock. Another aspect of energy security is addressed by Singh and Rao, who, having accepted that there is no getting away from fossil fuelbased electricity generation in the near future, suggest means of cleaner electricity generation from coal-fired power plants.

Sustainability issues know no state or national boundaries. The political economy of Trans-boundary Rivers is highlighted by Ghosh as he highlights the critical linkages among ecosystem services and livelihoods asserting that the dominant reductionist engineering perspective has led to a hydro-political situation of disputes. This critical challenge of environmental security is illustrated through the trans-boundary water relations between India and Bangladesh.

In their case study, Das, Giri and Ghosh present results from an (ongoing) interesting experiment to promote bio-intensive farming in 50 villages in the Bankura district of West Bengal. The farmers' responses clearly illustrate the tradeoffs between organic farming and water-intensive pesticide and fertilizer-based farming practices, and highlight the challenges for policy makers who seek to increase the adoption of bio-intensive farming practices.

Bhattacharya critically assesses an edited book by Ian Scoones, Melissa Leach and Peter Newell, titled the Politics of Green Transformation which advances the call for a pluralist approach to the transformation, echoing the nexus approach to managing critical resources that we are advocating. Sarada Devi is left a little disappointed by Karin Ekstrom's edited book titled Waste Management and Sustainable Consumption because of their exclusive focus on the developed world at a time when the rate of increase of wastes from developing countries like India and China is far higher than their developed counterparts.

This issue is by no means a comprehensive account of all the issues related the Managing Critical Issues: Food, Water and Energy, and, given the nature of the topic of the special issue, this was never the intent. Contributions for this special issue have come from litterateurs, engineers, social scientists, development specialists and practitioners. The richness of the articles is derived from this diversity as we see the same issues as they are viewed from different lenses. It is hoped that readers will be provoked to think differently, using a systems thinking ecosystem approach, about these critical resources, keeping in mind the bigger picture of the constraints of Spaceship Earth.

\section{References}

UN General Assembly (2010) Resolution adopted by the general assembly. The right to food (A/RES/64/159) 